\title{
Frequency of Obesity and Overweight in General Population
}

\author{
Muhammad Adrees, ${ }^{1}$ Muhammad Zeeshan Riaz, ${ }^{2}$ Hafiz Mughees Ather, ${ }^{3}$ Muhammad Aamer, ${ }^{4}$ Marjaan Noor, ${ }^{5}$ Afnan Noor 6 \\ 1,3,4Department of Medicine, Faisalabad Medical University, Faisalabad-Pakistan, 25,6Department of Cardiology, Faisalabad Institute of Cardiology, Faisalabad-Pakistan
}

\begin{abstract}
Objective: To determine frequency of obesity and overweight indoor patients in tertiary care hospital and to compare the results with international studies. Study Design: Cross Sectional Descriptive Case Series. Settings: In outdoor patients of medicine department Allied hospital Faisalabad. Duration: 6 months from 01-08-2018 to 31-01 -2019. Methodology: Adult patients of either gender were included in the study. Patients of bed bound and on chemotherapy patients were excluded. Nonprobability consecutive sampling technique was used. After enrolment of patients according to criterion an informed consent was taken. Body weight and height were taken and BMI was calculated. Results: We Included 400 patients. Age ranged from $12-80$ years (mean $=40.50 \pm 15.2$ years). Out of these 400 patients $58.3 \%$ patients were found to have overweight and obesity. There were 261 females and 139 males. Age of patients ranged $12-80$ years (mean $=40.50 \pm 15.2$ years). Out of 400 patients $58.3 \%$ had obesity amongst which $70.4 \%$ were female and $29.6 \%$ were males and $P$ value regarding gender distribution was $(0.032)$ very significant showing strong association of gender and obesity and graph2 is showing that more than two third obese patients were females. In our data of 400 patients majority of patients in age above 30 years were obese and $P$ value regarding age distribution was $(0.001)$. very significant indicating important relationship between age and obesity. Conclusion: obesity and overweight are common in Pakistani population and needs to be considered in most of patients in outdoor patients especially females who are more predispose to having obesity and either gender with age above 30 years
\end{abstract}

Keywords: Obesity, Overweight, Females.

Corresponding Author

Submitted for Publication: 24-09-2019

Email: haroonadrees2010@gmail.com

Citation: Adrees M, Riaz MZ, Ather HM, Aamer M, Noor M, Noor A. Frequency of Obesity and Overweight in General Population. APMC 2020;14(2):136-9.

DOI: $10.29054 / A P M C / 2020.708$

\section{INTRODUCTION}

Obesity is overgrowing problem of the global community. Obesity refers to deposition of fat in excess in the body. The term overweight means an excess of body weight. Obesity is a chronic disease and is increasing in prevalence worldwide. There is global epidemic of obesity especially over the past 20 years. American population is expected to be $50 \%$ over weight and $25 \%$ obese during their life. ${ }^{1}$ Measuring body mass index (BMI) is the first important step to determine the degree of fat in the body. ${ }^{1}$

For Asians, overweight is taken as a BMI between 23 and 24.9 $\mathrm{kg} / \mathrm{m} 2$, and obesity is taken as BMI $>25 \mathrm{~kg} / \mathrm{m} 2$ and abdominal obesity is Waist Circumference $>90 \mathrm{Cm}$ irrespective of BMl.

In general, greater BMI is associated with increased rate of death from all causes and from cardiovascular diseases. Hypertension is one of the leading causes of morbidity and mortality among obese people. In one study, overweight and obesity accounted for $26 \%$ cases of hypertension in men when followed up to 44 years of age. With significant increase in obesity in last decade, prevalence of hypertension has also increased significantly. ${ }^{2}$

The data from the WHO suggests $65 \%$ of the world's population live in countries where overweight and obesity kills more people than underweight. The WHO defines -overweight as a BMI greater than or equal to 25 , and obesity as a BMI greater than or equal to 30 . Both overweight and obesity are major risk factors for heart disease and stroke and diabetes. A surrogate marker for body fat content is the body mass index (BMI), is measured by weight divided by height in square. A better way to define obesity would be in terms of percent total body fat. Based on BMI, prevalence should take the overweight and obesity of all inpatient and outpatient. Other studies states that more than $75 \%$ of population was having obesity and overweight in south coastal India. ${ }^{3,4}$

Obesity increases the risk of developing cardiovascular disease and diabetes. Obesity is a rapidly growing health problem in the world conferring substantial excess risk for morbidity and mortality. ${ }^{5}$ Characteristics of BMI-metabolic risk sub phenotypes have been described in selected study samples, from which the prevalence data has been collected from the respective hospital. Furthermore, both obesity and Metabolic syndrome are risk factors for type 2 diabetes but whether elevated BMI in their absence confers risk for type 2 diabetes is imprecise. ${ }^{5}$ The prevalence of obesity and metabolic syndrome is rapidly increasing in India and other South Asian countries have increased mortality and morbidity due to CVD and T2DM. The Asian Indian studies refer to the fact that high prevalence of diabetes and cardiovascular diseases is seen in people originating from South Asian nations. These disturbances include high FBS and increased levels of waist circumstances, low levels of high-density lipoprotein (HDL) and high levels of triglycerides, and hypertension. All of these risk factors have been taken as a metabolic syndrome. ${ }^{6,7}$ 
Obesity is a Major factor in development of hypertension, diabetes and other cardio metabolic conditions. Other than cardiometabolic condition obese patient has psychological issue even there are musculoskeletal conditions and newer research finding are showing obesity is associated more incidence of malignancies. Obese patients are four-fold increased risk of diabetes mellitus and hypertension and four-fold increased risk of cardiometabolic disorders in general patient have other disorders but with obesity, Obesity is also burden on economy of countries and adversely affect country and performance of different department due to obesity related issues. 8,9

Research is showing obesity from $12 \%$ to 40 in different parts of world in our study, is found to $30 \%$ which is comparable to Europe and Asian population and overweight patient are more. They are potential patient for future obesity and its related disorders. ${ }^{10,11}$

The aim of this study to assess the prevalence of obesity and overweight in both genders and to create awareness among adults regarding obesity and overweight.

\section{METHODOLOGY}

Study Design: Cross Sectional Descriptive Case Series. Settings: In outdoor patients of medicine department Allied hospital Faisalabad-Pakistan.

Duration: 6 months from 01-08-2018 to 31-01-2019.

Sampling Technique: Non probability consecutive sampling

Inclusion Criteria: Adult patients of either gender were included.

Exclusion Criteria: Patients who were bedbound and on chemotherapy were excluded from this study.

Data Collection Procedure: After selection of patient as per criterion, informed consent was taken. Then a brief history regarding demographic details, body weight and height and BMI was calculated. Patient's history of DM, Hypertension and smoking was recorded. The obesity finding in relation to age distributions is depicted in table 1

In this study WHO criteria for obesity and overweight was applied. After the data collection was accomplished, results were analyzed by SPSS version 21 .

\section{RESULTS}

Total number of patients was 400 . There were 261 females and 139 males. Age of patients ranged 12-80 years (mean = $40.50 \pm 15.2$ years). Out of total number of 400 patients $58.3 \%$ had obesity amongst which $70.4 \%$ were female and $29.6 \%$ were males and $P$ value regarding gender distribution was $(0.032)$ very significant showing strong association of gender and obesity and graph is showing that more than two third obese patients were females.

In our data of 400 patients, majority of patients in age above 30 years were obese and $P$ value regarding age distribution was (0.001). very significant indicating important relationship between age and obesity.

Table 1: Distribution of respondents according to their age

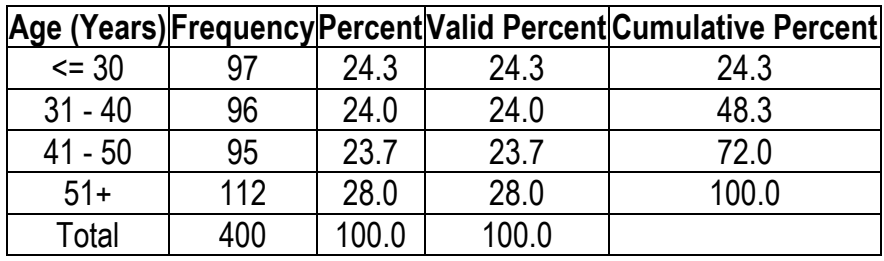

Table 2: Gender distribution of respondents

\begin{tabular}{|c|c|c|c|c|}
\hline Gender & Frequency & Percent & Valid Percent & Cumulative Percent \\
\hline Male & 139 & 34.7 & 34.7 & 34.7 \\
\hline Female & 261 & 65.3 & 65.3 & 100.0 \\
\hline Total & 400 & 100.0 & 100.0 & \\
\hline
\end{tabular}

Table 3: Distribution of respondents according to their body mass index

\begin{tabular}{|c|c|c|c|c|}
\hline BMI group & Frequency & Percent & $\begin{array}{c}\text { Valid } \\
\text { Percent }\end{array}$ & $\begin{array}{c}\text { Cumulative } \\
\text { Percent }\end{array}$ \\
\hline Under weight & 8 & 2.0 & 2.0 & 2.0 \\
\hline Normal weight & 159 & 39.7 & 39.7 & 41.7 \\
\hline Over weight & 120 & 30.0 & 30.0 & 71.7 \\
\hline Grade I obesity & 84 & 21.0 & 21.0 & 92.7 \\
\hline Grade 2 Obesity & 20 & 5.0 & 5.0 & 97.7 \\
\hline Morbid Obesity & 9 & 2.3 & 2.3 & 100.0 \\
\hline Total & 400 & 100.0 & 100.0 & \\
\hline
\end{tabular}

Table 4: Relationship between BMI Group and age group

\begin{tabular}{|c|c|c|c|c|c|c|}
\hline \multirow{2}{*}{\multicolumn{2}{|c|}{ BMI Group }} & \multicolumn{4}{|c|}{ Age group } & \multirow{2}{*}{ Total } \\
\hline & & $<=30$ & $31-40$ & $41-50$ & $51+$ & \\
\hline \multirow{3}{*}{$\begin{array}{l}\text { Under } \\
\text { weight }\end{array}$} & Count & 4 & 2 & 1 & 1 & 8 \\
\hline & $\%$ within $\mathrm{BMI}$ & $50.0 \%$ & $25.0 \%$ & $12.5 \%$ & $12.5 \%$ & $100.0 \%$ \\
\hline & $\%$ within Age group & $4.1 \%$ & $2.1 \%$ & $1.1 \%$ & $0.9 \%$ & $2.0 \%$ \\
\hline \multirow{3}{*}{$\begin{array}{l}\text { Normal } \\
\text { weight }\end{array}$} & Count & 51 & 31 & 29 & 48 & 159 \\
\hline & \% within BMI & $32.1 \%$ & $19.5 \%$ & $18.2 \%$ & $30.2 \%$ & $100.0 \%$ \\
\hline & $\%$ within Age group & $52.6 \%$ & $32.3 \%$ & $30.5 \%$ & $42.9 \%$ & $39.8 \%$ \\
\hline \multirow{3}{*}{$\begin{array}{l}\text { Over } \\
\text { weight }\end{array}$} & Count & 19 & 34 & 35 & 32 & 120 \\
\hline & $\%$ within BMl & $15.8 \%$ & $28.3 \%$ & $29.2 \%$ & $26.7 \%$ & $100.0 \%$ \\
\hline & $\%$ within Age group & $19.6 \%$ & $35.4 \%$ & $36.8 \%$ & $28.6 \%$ & $30.0 \%$ \\
\hline \multirow{3}{*}{$\begin{array}{l}\text { Grade I } \\
\text { obesity }\end{array}$} & Count & 17 & 21 & 23 & 23 & 84 \\
\hline & $\%$ within BMI & $20.2 \%$ & $25.0 \%$ & $27.4 \%$ & $27.4 \%$ & $100.0 \%$ \\
\hline & $\%$ within Age group & $17.5 \%$ & $21.9 \%$ & $24.2 \%$ & $20.5 \%$ & $21.0 \%$ \\
\hline \multirow{3}{*}{$\begin{array}{l}\text { Grade } 2 \\
\text { Obesity }\end{array}$} & Count & 5 & 1 & 7 & 7 & 20 \\
\hline & $\%$ within BMI & $25.0 \%$ & $5.0 \%$ & $35.0 \%$ & $35.0 \%$ & $100.0 \%$ \\
\hline & $\%$ within Age group & $5.2 \%$ & $1.0 \%$ & $7.4 \%$ & $6.3 \%$ & $5.0 \%$ \\
\hline \multirow{3}{*}{$\begin{array}{l}\text { Morbid } \\
\text { Obesity }\end{array}$} & Count & 1 & 7 & 0 & 1 & 9 \\
\hline & \% within BMl & $11.1 \%$ & $77.8 \%$ & $0.0 \%$ & $11.1 \%$ & $100.0 \%$ \\
\hline & $\%$ within Age group & $1.0 \%$ & $7.3 \%$ & $0.0 \%$ & $0.9 \%$ & $2.3 \%$ \\
\hline \multirow{3}{*}{ Total } & Count & 97 & 96 & 95 & 112 & 400 \\
\hline & $\%$ within $\mathrm{BMI}$ & $24.3 \%$ & $24.0 \%$ & $23.8 \%$ & $28.0 \%$ & $100.0 \%$ \\
\hline & $\%$ within Age gro & 100.0 & $100.0^{\circ}$ & $100.0^{\circ}$ & $100.0^{\circ}$ & 100.0 \\
\hline
\end{tabular}

Chi-square value $=37.01^{* *} ;$ P-value $=\mathbf{0 . 0 0 1}$

NS $=$ Non-significant $(P>0.05) ;{ }^{*}=$ Significant $(P<0.05) ;{ }^{* *}=$ Highly significant $(P<0.01)$ 


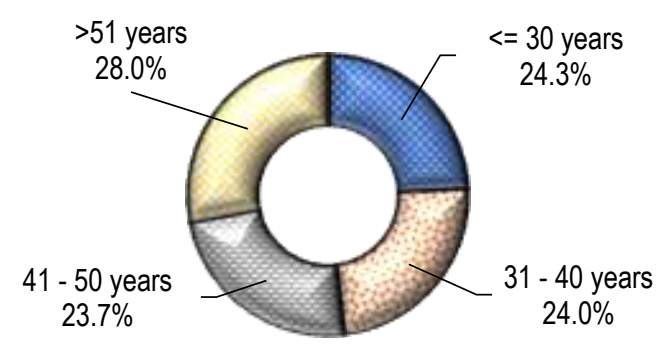

Figure 1: Age group distribution

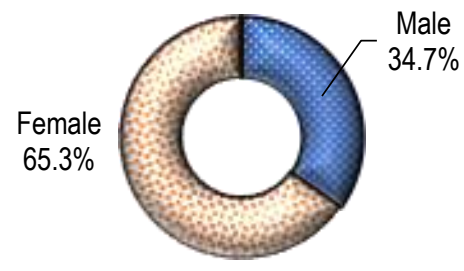

Figure 2: Gender distribution

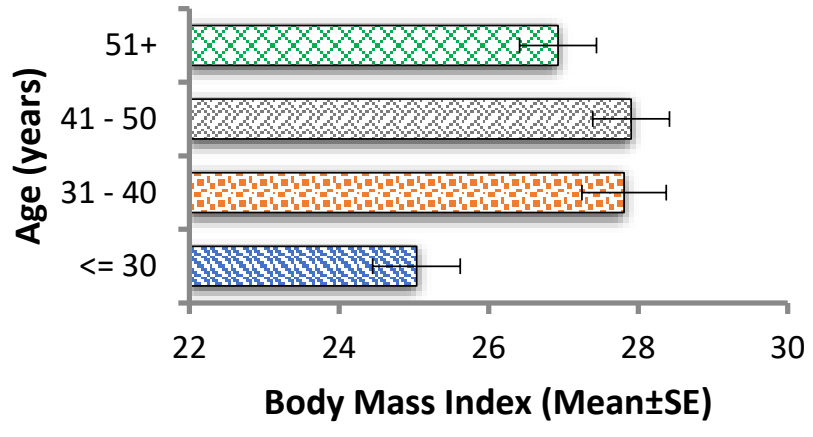

Figure 5: Age distribution

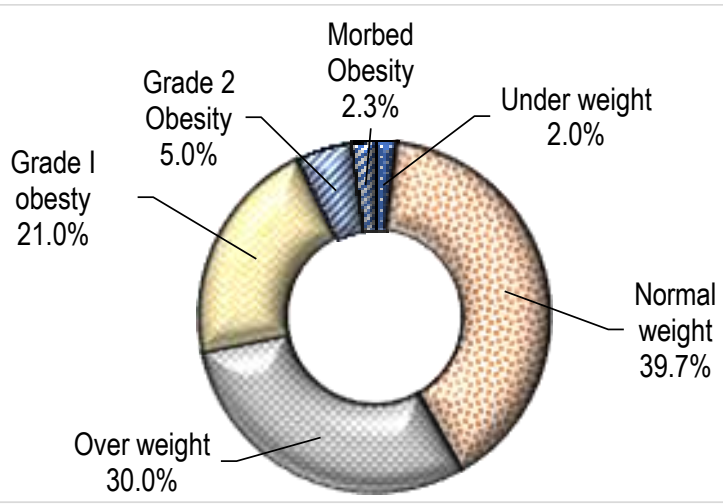

Figure 7: Body mass index (BMI) with different grades of obesity

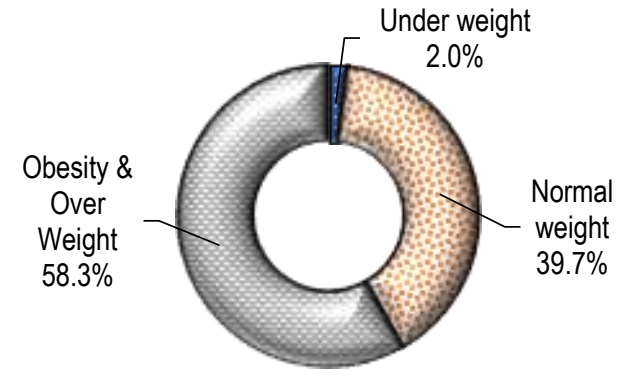

Figure 8: Body mass index (BMI) and percentage of obesity and overweight

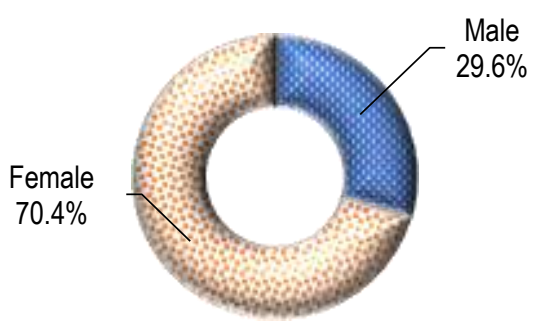

Figure 9: Obesity in male and female

Table 5: Relationships between BMI Group and Gender

\begin{tabular}{|c|c|c|c|c|}
\hline \multirow{2}{*}{\multicolumn{2}{|c|}{ BMI Group }} & \multicolumn{2}{|c|}{ Gender } & \multirow{3}{*}{$\begin{array}{c}\text { Total } \\
8\end{array}$} \\
\hline & & \multirow{2}{*}{$\begin{array}{c}\text { Male } \\
3\end{array}$} & \multirow{2}{*}{$\begin{array}{c}\text { Female } \\
5\end{array}$} & \\
\hline \multirow{3}{*}{$\begin{array}{l}\text { Under } \\
\text { weight }\end{array}$} & Count & & & \\
\hline & $\%$ within $\mathrm{BMI}$ & $37.5 \%$ & $62.5 \%$ & $100.0 \%$ \\
\hline & $\%$ within Gender & $2.2 \%$ & $1.9 \%$ & $2.0 \%$ \\
\hline \multirow{3}{*}{$\begin{array}{l}\text { Normal } \\
\text { weight }\end{array}$} & Count & 67 & 92 & 159 \\
\hline & $\%$ within $\mathrm{BMI}$ & $42.1 \%$ & $57.9 \%$ & $100.0 \%$ \\
\hline & $\%$ within Gender & $48.2 \%$ & $35.2 \%$ & $39.8 \%$ \\
\hline \multirow{3}{*}{$\begin{array}{c}\text { Over } \\
\text { weight }\end{array}$} & Count & 42 & 78 & 120 \\
\hline & $\%$ within BMI & $35.0 \%$ & $65.0 \%$ & $100.0 \%$ \\
\hline & $\%$ within Gender & $30.2 \%$ & $29.8 \%$ & $30.0 \%$ \\
\hline \multirow{3}{*}{$\begin{array}{l}\text { Grade I } \\
\text { obesity }\end{array}$} & Count & 22 & 62 & 84 \\
\hline & $\%$ within BMI & $26.2 \%$ & $73.8 \%$ & $100.0 \%$ \\
\hline & $\%$ within Gender & $15.8 \%$ & $23.8 \%$ & $21.0 \%$ \\
\hline \multirow{3}{*}{$\begin{array}{l}\text { Grade } 2 \\
\text { Obesity }\end{array}$} & Count & 5 & 15 & 20 \\
\hline & $\%$ within BMI & $25.0 \%$ & $75.0 \%$ & $100.0 \%$ \\
\hline & $\%$ within Gender & $3.6 \%$ & $5.7 \%$ & $5.0 \%$ \\
\hline \multirow{3}{*}{$\begin{array}{l}\text { Morbid } \\
\text { Obesity }\end{array}$} & Count & 0 & 9 & 9 \\
\hline & $\%$ within $\mathrm{BMI}$ & $0.0 \%$ & $100.0 \%$ & $100.0 \%$ \\
\hline & $\%$ within Gender & $0.0 \%$ & $3.4 \%$ & $2.3 \%$ \\
\hline \multirow{3}{*}{ Total } & Count & 139 & 261 & 400 \\
\hline & \% within BMl & $34.7 \%$ & $65.3 \%$ & $100.0 \%$ \\
\hline & $\%$ within Gender & $100.0 \%$ & $100.0 \%$ & $100.0 \%$ \\
\hline
\end{tabular}

Chi-square value $=12.20^{*} ; \mathrm{P}$-value $=0.032$

NS = Non-significant $(P>0.05) ;{ }^{*}=$ Significant $(P<0.05) ;{ }^{* *}=$ Highly significant $(P<0.01)$ 


\section{DISCUSSION}

Obesity in a very common chronic disease with significant morbidity and mortality and is fifth leading cause of death globally. Without active screening patients may have silent killing diseases like hypertension, diabetes and metabolic syndrome.

In a study conducted by Sumanth, Ramya $\mathrm{N}$ et al in pharmacy department Reddy memorial college published in world journal of pharmacy in May 2016. Data was collected from tertiary care hospital and this study was done on 353 patients with male 196 and females were 157 . The study showed $42.4 \%$ patient were overweight and $35.97 \%$ were obese which is comparable to our study which showed that $30 \%$ patients were overweight and $28.5 \%$ were obese. ${ }^{12}$

In another study by Salazar-Sepulveda LL et al in department of internal medicine during 2016-2017 on 316 Patients and obesity was found to be in $18.8 \%$ patients which is comparable to our study showing $28.3 \%$ obesity in 400 patients. ${ }^{13}$

In a study by Ali $Z$ et al was conducted on 387 patients with mean ages 52 years in Diabetic Clinic of medical Unit 3 Jinnah Postgraduate medical Centre Karachi. In this study, males were $128(33 \%)$ and females were 259 and (80\%) of females patients were found to having obesity which is comparable to our finding with $70.4 \%$ of females patients. ${ }^{14}$

In another study conducted by Huang $\mathrm{J}$ et al in public hospital in Louisiana state university health science center. In this study 1507 patients were included and $81 \%$ of patient were found to have overweight or obese which is slightly higher than our 58.3 $\%$ of patients with obesity and this may be regional difference and may be due to a reason that large population of more than 1500 patients were included in this study. ${ }^{15}$

\section{CONCLUSION}

We can conclude that obesity is common finding in patients outdoor patients in tertiary care hospital and screening should be done in all patients because $58.3 \%$ is an important finding.

\section{LIMITATIONS}

The data collected from only medicine department. Patients may have presented in other departments as well. Frequency of obese patients may vary in other departments.

\section{SUGGESTIONS / RECOMMENDATIONS}

More than half of patients were overweight or obese in our study and we recommend to take measures for prevention and management of obesity in all patients. So that we can prevent the future complications of overweight and obesity.

\section{CONFLICT OF INTEREST / DISCLOSURE}

None.

\section{ACKNOWLEDGEMENTS}

We are thankful to all our collages, patients and technical support from IT Department of Faisalabad Medical University, Faisalabad-Pakistan.

\section{REFERENCES}

1. Kaur J. A comprehensive review on metabolic syndrome. Cardiol Res Pract. 2014;(9):1-21.

2. New Obesity. Type 2 Diabetes Gene Identified. Medical News Today. Medi Lexicon, Intl. 11 Jan. 2013.

3. Brunetti $A$, Chiefari $E$, Foti $D$. Recent advances in the molecular genetics of type 2 diabetes mellitus. World J Diabetes. 2014;5(2):128-40.

4. Singh V, Singh M, Joshi A, Joshi C. Prevalence of different components of the metabolic syndrome in type 2 diabetics attending tertiary care hospital in Himalayan region. IJRMS. 2017;5(12):5232-6.

5. Osuji CU, Nzerem BA, Dioka CE, Onwubuya El. Metabolic syndrome in newly diagnosed type 2 diabetes mellitus using NCEP-ATP III, the Nnewi experience. Nigerian J Clinic Practice. 2012;15(4):475-80.

6. Zhou L, Stamler J, Chan Q, Horn LV, Daviglus ML, Dyer AR, et al. Salt intake and prevalence of overweight/obesity in Japan, China, the United Kingdom, and the United States: The INTERMAP Study. Am J Clin Nutr. 2019;110(1):34-40.

7. Mahé E, Maccari F, Ruer-Mulard M, Bodak N, Barthelemy H, Nicolas C, et al. Children with psoriasis in secondary care: Clinical aspects and comorbidities diverge from the generally published data. Ann Dermatol Venereol. 2019;146(5):354-62.

8. Biadgo B, Melak T, Ambachew S, Baynes HW, Limenih MA, Jaleta KN et al. The Prevalence of Metabolic Syndrome and Its Components among Type 2 Diabetes Mellitus Patients at a Tertiary Hospital, Northwest Ethiopia. Ethiop J Health Sci. 2018;28(5):645-54.

9. Mogili KD, Karuppusami R, Thomas S, Chandy A, Kamath MS, Tk A. Prevalence of vitamin $D$ deficiency in infertile women with polycystic ovarian syndrome and its association with metabolic syndrome - A prospective observational study. Eur J Obstet Gynecol Reprod Biol. 2018;229:15-9.

10. Arambewela MH, Somasundaram NP, Jayasekara HBPR, Kumbukage MP, Jayasena PMS, et al. Prevalence of Chronic Complications, Their Risk Factors, and the Cardiovascular Risk Factors among Patients with Type 2 Diabetes Attending the Diabetic Clinic at a Tertiary Care Hospital in Sri Lanka. J Diabetes Res. 2018;4(1)1-10.

11. Owolabi EO, Ter Goon D, Adeniyi OV. Central obesity and normalweight central obesity among adults attending healthcare facilities in Buffalo City Metropolitan Municipality, South Africa: a cross-sectional study. J Health Popul Nutr. 2017;36:54.

12. Sumanth N, Ramya N, Venkatesh J, Lokesh Reddy V, et al. Prevalence of obesity and metabolic syndrome among adults in tertiary care hospitals of coastal andhra. Int J Pharm. 2016; 5(6):1242-56.

13. Salazar-Sepúlveda LL, Villarreal-Pérez JZ. Impact of diagnosis of overweight and obesity on weight management among hospitalized patients. Obes Res Clin Pract. 2019;13(2):164-7.

14. Ali Z, Ahmed SM, Nageen A, et al. Obesity \& Diabetes: An experience at a public sector tertiary care hospital. Pak J Med Sci. 2014;30(1):81-5.

15. Huang J, Marin E, Yu H, Carden D, Arnold C, Davis T, Banks D. Prevalence of overweight, obesity, and associated diseases among outpatients in a public hospital. South Med J. 2003;96(6):558-62.

\section{AUTHORSHIP CONTRIBUTION}

Muhammad Adrees

Muhammad Zeeshan Riaz

Hafiz Mughees Ather

Muhammad Aamer

Marjaan Noor

Afnan Noor
Data Collection, Manuscript writing

Data Collection

Statistical Analysis

Data Interpretation

Discussion writing

Results and References 